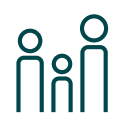

Public Health

\section{0}

CiteScore: 1.2

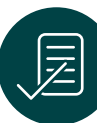

Acceptance rate $\mathbf{5 7 \%}$

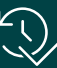

Time to final decision 13 weeks

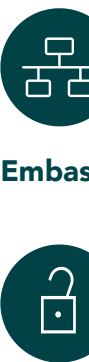

DOAJ

\title{
Portuguese Journal of Public Health
}

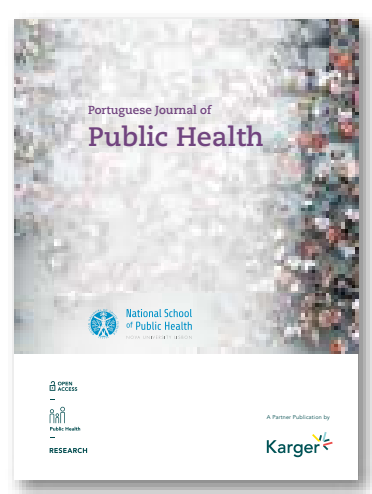

O OPEN

A Partner Publication by Karger

Editor-in-Chief

António Sousa Uva (Lisbon)

Your source for information on public health and related disciplines

This journal publishes scientific content in the field of public health in general as well as related disciplines, with the aim to promote the discussion and development of knowledge at a national and international level. One special topic issue per year concentrates on a topic of general health interest such as primary care, health economics, new models in health management, or occupational health. The journal publishes original articles, reviews, editorials, and opinion articles.

PJPH.Journal@ ensp.unl.pt

karger.com/pjp

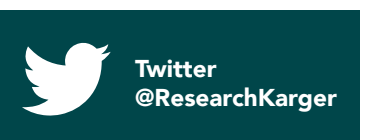

